\title{
EVALUASI RENCANA PEMBELAJARAN SEMESTER MATA KULIAH NIHONJIJO DAN SEMINAR DESAIN SKRIPSI
}

\author{
Evaluation of Semester Learning Plan \\ on The Nihonjijo Course, Kaiwa Chukyu Kohan Course, \\ and Thesis Design Seminar Cours
}

Lispridona Diner

Universitas Negeri Semarang,

Semarang, Jawa Tengah,

Indonesia

*email: lisjoost@yahoo.coml

correspondence author

\section{Kata Kunci:}

Evaluasi I

Rencana Pembelajaran

Semester 2

Keywords:

Evaluation I

Semester Learning Plan 2

\begin{abstract}
Abstrak
Rencana Pembelajaran Semester (RPS), disusun berdasarkan kebutuhan yang ada saat ini, informasi ini kami terima dari stake holder, dan juga mengikuti tuntutan yang ditetapkan oleh UNNES sendiri. Untuk mengetahui, RPS tersebut dapat digunakan lagi pada semester selanjutnya, maka penyusunan RPS perlu dilakukan evaluasi.

Tujuan dari evaluasi terhadap RPS untuk mengetahui apakah RPS yang telah disusun perlu diperbaiki dan bisa digunakan atau tidak lagi bisa digunakan pada tahun ajaran berikutnya. RPS yang dievaluasi pada artikel ini adalah RPS mata kuliah seminar desain skripsi, mata kuliah nihonjijo dan mata kuliah kaiwa chukyu kohan. RPS dievaluasi mengacu pada KKNI dan nilai-nilai konservasi UNNES.

Berdasarkan hasil evaluasi, maka RPS mata kuliah seminar desain skripsi dan mata kuliah kaiwa chukyu kohan perlu adanya revisi pada CPMK, nilai-nilai konservasi UNNES digambarkan sesuai dengan FBS. Sedangkan RPS mata kuliah nihonjijo perlu adanya revisi pada CPL mengacu KKNI dan CPMK disusun dengan menggambarkan nilai-nilai konservasi FBS.
\end{abstract}

\begin{abstract}
The Semester Learning Plan (RPS), prepared based on current needs, we received this information from the stake holders, and also followed the demands set by UNNES itself. To find out, the RPS can be used again in the next semester, then the preparation of the RPS needs to be evaluated. The purpose of the evaluation of the RPS is to find out whether the RPS that has been prepared needs to be improved and can be used or can no longer be used in the next school year. The RPS evaluated in this article are the RPS of the thesis design seminar course, the nihonijo course and the kaiwa chukyu kohan course. The RPS is evaluated based on KKNI and UNNES conservation values. Based on the evaluation results, the RPS of the thesis design seminar course and the kaiwa chukyu kohan course need a revision in the CPMK, UNNES conservation values are described in accordance with FBS. While the nihonijo course needs to be revised on CPL referring to $K K N I$ and CPMK prepared by describing the conservation values of FBS.
\end{abstract}




\section{PENDAHULUAN}

Setiap tahun dalam menerapkan sistem pembelajaran selalu mengalami perbaikan yang dikarenakan oleh kebutuhan masyarakat atau stake holder. Akhir-akhir ini, sumber daya manusia dituntut untuk memiliki kemampuan yang baik pada bidang softskill yang mencakup misalnya; kerja sama dalam tim atau kelompok, pekerja keras, disiplin, jujur dan dapat dipercaya. Selain tentunya memiliki kemampuan pokok atau hardskill. Oleh karena itu, dalam mempersiapkan kemampuan yang tahan uji dalam dunia kerja atau kelompok masysrakat pada bidang hardskill dan soft skill, maka dalam proses persiapannnya tersebut dibutuhkan metode yang tepat agar mampu menghasilkan kemampuan yang baik dan memiliki daya saing yang tinggi. Sehubungan dengan proses mempersiapkan kemampuan tersebut, tentu saja berkaitan dengan upaya merancang sebuah sistem pembelajaran yang baik. Apabila mengacu pada ketentuan lembaga perguruan tinggi yaitu Universitas Negeri semarang (UNNES), maka seluruh staff pengajar dilingkungan UNNES dianjurkan untuk menerapkan sistem pembelajaran yang berpusat pada peserta didik atau disebu dengan SCL (Student Center Learning). Didasarkan pada tuntutan tersebut, maka pada saat menyusun rancangan pembelajaran sedapat mungkin menggunakan metode pembelajaran yang berbasis pada SCL, dan pengajaran yang dapat mengasah kemampuan hard skill dan soft skill peserta didik.

Berdasarkan fenomena di atas, maka dapat dikatakan perlu melaksanakan perkuliahan yang dapat memberikan capaian kompetensi seperti yang diharapkan, maka harus ada tuntunan, yang dalam hal ini berupa rancangan pembelajaran yang disusun secara runtut dan sistematis. Rencana Pembelajaran Semester (RPS), disusun berdasarkan kebutuhan masyarakat di dunia kerja atau stake holder, dan juga mengikuti tuntutan yang ditetapkan oleh UNNES sendiri. Selain itu, RPS juga berguna sebagai panduan bagi peserta didik dalam mengikuti proses pembelajaran dan agar peserta didik dapat mempersiapkan diri dalam pelaksanaan proses pembelajaran tersebut (Abdul, 20II).

Jadi Rencana Pembelajaran Semester adalah sebuah rancangan pembelajaran yang disusun oleh dosen secara individu atau dengan dosen lain sesuai dengan keahlian bidangnya. RPS digunakan sebagai rencana pembelajaran I semester.

Dalam RPS tertulis bagaimana cara peserta didik agar dapat memperoleh nilai terbaik. Selain itu, peserta didik juga dapat mengetahui kompetensi apa yang akan mereka peroleh setiap pertemuan, serta bahan bacaan apa yang harus mereka baca sebagai bekal untuk mengikuti perkuliahan yang dimaksud (Sitepu \& Ika, 2018). Sehubungan dengan mata kuliah dalam program studi pendidikan bahasa Jepang, maka peserta secara umum dapat mengetahui kompetensi akhir yang akan mereka peroleh adalah kemampuan menyerap informasi yang terdapat dalam RPS sebagai panduan peserta didik mengikuti perkuliahan selama satu semester. RPS pada lingkungan UNNES disusun sesuai kurikulum KKNI yang sedang diberlakukan pada pendidikan Tinggi Indonesia

\section{Definisi KKNI}

Kurikulum KKNI (Kerangka Kualifikasi Nasional Indonesia) adalah kerangka penjenjangan kualifikasi yang dapat menyetarakan, menyandingkan dan mengintegrasikan bidang pendidikan dan bidang pelatihan kerja maupun pengalaman kerja dalam pemberian pengakuan kompetensi kerja dari berbagai sektor (Sanusi, 2016). Kurikulum berbasis KKNI memiliki makna perubahan dalam pelaksanaan pembelajaran, penciptaan suasana akademik, dan cara evaluasi dalam menunjang tujuan pendidikan, dan kurikulum memiliki peran sebagai kebijakan 
menajemen pendidikan tinggi yang dapat digunakan untuk menentukan arah pendidikan. Pada penerapan kurikulum berbasis KKNI ini diharapkan kualitas pendidikan di Indonesia semakin maju, karena KKNI ini merupakan kerangka acuan yang dijadikan ukuran dalam pengakuan penjenjangan suatu lembaga kependidikan. KKNI disusun dalam rangka menciptakan standar lulusan yang dapat diakui secara nasional dengan harapan mampu bersaing di luar negeri. Definisi KKNI di atas diatur dan tertuang dalam PerPres No.8 Tahun 2014 tentang KKNI

Di lingkungan UNNES RPS dibuat oleh pengajar mengacu pada kurikulum yang terdapat dalam setiap program studi. Kurikulum merupakan salah satu sistem yang mengatur jalannya pendidikan dan sebagai panduan dalam jalannya sebuah pembelajaran. Pembentukan sebuah kurikulum harus mampu menjawab tuntutan dari masyarakat. Melalui kurikulum akan menentukan kualitas dan arah dalam suatu pembelajaran. Selain itu kurikulum juga harus menyesuaikan dengan era tertentu. Dalam kurikulum ada visi misi tertentu, begitu pula dengan adanya beberapa perubahan yang dilakukan oleh suatu lembaga pendidikan atau pengguna kurikulum. Dalam satu kurikulum akan mempunyai visi misi yang berbeda dengan kurikulum yang lainnya. Maka dari itu dengan dilakukan perubahan kurikulum diharapkan agar proses atau tuntutan pembelajaran semakin baik kedepannya. Dalam pembuatan kurikulum menggunakan pedoman yang sesuai dan diatur dalam Keputusan Menteri Pendidikan Nasional Republik Indonesia no. 232/u/2000 tentang penyusunan kurikulum dan hasil belajar mahasiswa. Dalam pasal I ayat 5 Keputusan Menteri Pendidikan Nasional Republik Indonesia no. 232/u/2000 tentang program studi sebagai pedoman dan alat penyelenggaraan akademik yang bertujuan agar mahasiswa dapat memiliki pengetahuan, keterampilan dan sikap yang sesuai dengan kurikulum. Seperti kurikulum KKNI yang merupakan kerangka acuan yang dijadikan acuan dalam jenjang pendidikan dan sebagai penyanding, penyetaraan dan pengintegrasian antara bidang pendidikan dan pelatihan kerja dalam pemberian pengakuan dalam kompetensi kerja sesuai dengan struktur.

Pada kurikulum KKNI yang tertera pada Perspres No. 49 tahun 2014 pemendikbud No. 73 tahun 2013 tentang capaian pembelajaran sesuai dengan level KKNI. UU PT No. 12 tahun 2012 pasal 29 tentang kompetensi lulusan yang mengacu pada KKNI. Maka capaian pembelajaran setiap mata kuliah harus mengacu pada KKNI. Pada program studi Pendidikan Bahasa Jepang yang sudah melakukan perubahan kurikulum sebanyak tiga kali, yaitu pertama menggunakan kurikulum 20II, kedua menggunakan kurikulum 2014 dan yang terakhir menggunakan kurikulum KKNI (Kerangka Kualifikasi Nasional Indonesia). Tentu dalam perubahan kurikulum diharapkan untuk

pembelajaran lebih baik. Perubahan kurikulum akan mempengaruhi beberapa faktor, seperti proses pengajaran di kelas, capaian pembelajaran, kemampuan mahasiswa hingga penilaian. Dalam kurikulum KKNI dapat dikatakan pembelajaran berpusat pada mahasiswa (student center), sehingga pembelajar dituntut untuk lebih mendekatkan diri pada proses pembelajaran. Pembelajaran yang dimaksud adalah mahasiswa yang diberikan suatu materi kemudian harus menemukan masalah dalam materi tersebut, memecahkan masalah dalam materi tersebut hingga mendapat jawaban pada masalah tersebut.

\section{Nila-Nilai Konservasi UNNES}

CPL yang terdapat dalam RPS menggambarkan nilainilai konservasi UNNES. Universitas Negeri Semarang adalah salah satu perguruan tinggi yang menobatkan diri sebagai Universitas Konservasi. Konservasi sendiri memiliki arti yaitu usaha melindungi dan melestarikan nilai budaya dan perilaku manusia dalam berinteraksi 
dengan lingkungan (Retnnoningsih \& Dkk, 2019). Nilainilai karakter peserta didik dalam menghidupkan konservasi yang penyebarannya pada setiap fakultas di lingkungan UNNES mencakup (Yuniawan, 2016) :

I. Inspiratif, pada FIP (Fakultas IImu Pendidikan)

Memiliki ide atau gagasan untuk bertindak, melakukan sesuatu dengan sengaja tanpa mengenal waktu,tempat,dan kondisi.

2. Humanis, pada FBS (Fakultas Bahasa dan Seni)

Menghargai orang lain,mengharapkan, dan memperjuangkan terwujudnya pergaulan hidup yang lebih baik dengan berdasarkan atas asas kemanusiaan.

3. Peduli, pada FIS (Fakultas IImu Sosial)

Kemampuan mengindahkan, memperhatikan, dan menghiraukan. Peduli lingkungan adalah sikap dan tindakan yang selalu berupaya mencegah kerusakan lingkungan dan mengembangkan upaya untuk memperbaiki kerusakan lingkungan. Peduli sosial adalah sikap dan tindakan yang selalu ingin memberi bantuan pada orang lain dan masyarakat yang membutuhkan.

4. Inovatif, pada FMIPA (Fakultas Matematika dan IImu Pengetahuan Alam)

Kemampuan mendayagunakan pemikiran, imajinasi, stimulan dan lingkungan dalam menghasilkan produk baru (pembaruan).

\section{Sportif, pada FIK (Fakultas Ilmu Keolahragaan)}

Bersifat ksatria, jujur. Adil terhadap lawan, bersedia mengakui keunggulan,kekuatan, kebenaran lawan, atau kekalahan, kelemahan, kesalahan sendiri.

6. Kreatif, pada FT (Fakultas Teknik)

Kemampuan berpikir dan bertindak untuk menyelesaikan masalah dengan cerdas dan mampu menghasilkan hal baru.

7. Jujur, pada FE (Fakultas Ekonomi)

Menjadi pribadi yang dapat dipercaya baik dalam perkataan, tindakan, maupun pekerjaan.

8. Adil , pada FH (Fakultas Hukum)

Tidak berpihak pada yang salah, berpihak pada yang benar.
Pada dasarnya nilai-nilai di atas tidak terpaku pada pelaksanaan pada satu fakultas saja. Semua nila-niai di atas dapat wujudkan pada semua fakultas.Dalam menerapkan nilai-nilai konservasi UNNSE membutuhkan kesadaran diri dari setiap individu. Bukan hanya bagi peserta didik saja tetapi semua pihak keluarga Universitas Negeri Semarang agar memorandum di atas dapat diterapkan.

\section{METODOLOGI}

Metode yang digunakan adalah metode deskripif, peneliti mendeskripsikan hasil evaluasi RPS mengacu pada KKNI dan nilai-nilai konservasi. Teknik pengumpulan data menggunakan teknik dokumentasi. Sumber data yang digunakan adaah RPS mata kuliah Nihonjijo, Kaiwa Chukyu Kohan dan Seminar Desain Skripsi. Evaluasi terhadap RPS dilakukan bertujuan mengetahui apakah RPS tersebut memerlukan perbaikan untuk dilanjutkan atau diganti sesuai dengan kebutuhan pembelajar bahasa Jepang saat ini.

\section{HASIL DAN PEMBAHASAN}

Evaluasi terhadap RPS berdasarkan acuan KKNI dan nilai-nilai konservasi UNNES. Terdapat tiga RPS yang dianalisis yaitu RPS mata kuliah nihonjijo, mata kuliah seminar desain skripsi dan mata kuliah kaiwa chukyu kohan.

Evaluasi RPS mata kuliah seminar desain skripsi.

\section{Acuan KKNI}

CPL sikap mengacu pada KKNI yakni poin I. Bertakwa kepada Tuhan yang Maha Esa dan menunjukkan sikap religius dan poin 8 . Menginternalisasi nilai, norma, dan etika akademik.

CPL keterampilan khusus mengacu pada KKNI poin I. mampu menerapkan pemikiran logis, kritis, sistematis, dan inovatif dalam konteks pengembangan atau implementasi ilmu pengetahuan dan teknologi yang 
memperhatikan dan menerapkan nilai humaniora bidangpendidikan bahasa Jepang.

CPL keterampilan umum mengacu pada $\mathrm{KKNI}$ poin 2. mampu menganalisis dan menerapkan teori, konsep, pendekatan dalam pembelajaran bahasa Jepang; serta menghasilkan desain pembelajaran yang inovatif untuk pembelajaran bahasa Jepang; dan poin 3. mampu merencanakan dan melakukan kajian terhadapimplementasi pendidikanbahasa Jepang melaluipendekatan secara terintegrasi; dan

CPL pengetahuan mengacu $\mathrm{KKNI}$ poin 2.1 menguasai konsep-konsep dasar kebahasaan, keterampilan berbahasa, pembelajaran bahasa, penelitian bahasa, serta penelitian pendidikan bahasa Jepang.

Nilai-nilai konservasi

Nilai konservasi UNNES terdapat pada Mampu menuliskan dan mempresentasikan proposal penelitian skripsi dengan menjunjung tinggi kesantunan dalam berbahasa dan berperilaku, serta menghargai pendapat orang lain.

RPS mata kuliah seminar desain skripsi disusun sesuai dengan KKNI dan dijabarkan secara jelas pada CPL pengetahuan, keterampilan khusus dan keterampilan umum. Dan CPMK terdapat nilai-nilai konservasi UNNES. Tetapi belum menggambarkan nilai-nilai konservasi FBS.

Evaluasi RPS mata kulian nihonjijo

\section{Acuan KKNI}

RPS ditulis sesuai dengan KKNI namun tidak dijelaskan poin-poin apa saja yang terdapat pada CPL perngetahuan, keterampilan umum dan khusus.

Nilai-nilai konservasi

Nilai-nilai konservasi UNNES tergambar pada CPMK, tetapi tidak tergambarkan pada setiap pertemuan.

RPS mata kuliah nihonjijo disusun belum sesuai dengan KKNI secara jelas dan perlu adanya revisi. Nilai-nilai konservasi UNNES belum menunjukkan nilai-nilai konsevasi FBS yaitu humanis.

Evaluasi RPS mata kuliah kaiwa chukyu kohan

Acuan KKNI

CPL sikap mengacu pada KKNI yakni poin I. Bertakwa kepada Tuhan yang Maha Esa dan menunjukkan sikap religius dan poin 8 . Menginternalisasi nilai, norma, dan etika akademik.

CPL keterampilan umum mengacu pada KKNI terdapat pada poin I. mampu menerapkan pemikiran logis, kritis, sistematis, dan inovatif dalam konteks pengembangan atau implementasi ilmu pengetahuan dan teknologi yang memperhatikan dan menerapkan nilai humaniora bidangpendidikan bahasa Jepang.

CPL keterampilan umum mengacu pada KKNI terdapat pada poin 2. mampu menganalisis dan menerapkan teori, konsep, pendekatan dalam pembelajaran bahasa Jepang; serta menghasilkan desain pembelajaran yang inovatif untuk pembelajaran bahasa Jepang; dan poin 3. mampu merencanakan dan melakukan kajian terhadap implementasi pendidikan bahasa Jepang melaluipendekatan secara terintegrasi;

CPL pengetahuan mengacu KKNI terdapat pada poin I.menguasai konsep-konsep dasar kebahasaan, keterampilan berbahasa, pembelajaran bahasa, penelitian bahasa, serta penelitian pendidikan bahasa Jepang;

Nilai-nilai konservasi

Nilai-nilai konservasi UNNES terdapat pada CPMK yakni poin I. Mampu menjelaskan dengan kalimat sederhana latar belakang pribadi, kondisi di sekitar diri sendiri, maupun yang berhubungan secara langsung dengan kebutuhan diri sendiri, 2. Mampu mengatasi sebagian besar keadaan yang terjadi saat perjalanan wisata di suatu wilayah di mana bahasa tersebut digunakan dan 3. Mampu menyatakan secara singkat mengenai pengalaman, peristiwa, impian, harapan, 
penjelasan, akan suatu ambisi, serta penjelasan akan suatu pendapat atau alasan dari sebuah perencanaan.

RPS mata kuliah kaiwa chukyu kohan telah disusun sesuai dengan $\mathrm{KKNI}$, dijelaskan setiap poin $\mathrm{CPL}$ pengetahuan, keterampilan umum dan khusus, sehingga mahasiswa dapat mengetahui apa yang akan dicapai melalui pembelajaran kaiwa chukyu kohan. CPMK kaiwa chukyu kohan disusun dengan jelas setiap poin mengacu pada deskripsi mata kuliah. Dengan ini mahasiswa dapat mengetahui target pembelajaran mata kuliah kaiwa chukyu kohan.

\section{KESIMPULAN}

Berdasarkan evaluasi 3 RPS di atas, maka dapat diketahui RPS yang mengacu KKN yang jelas setiap poin yakni RPS mata kuliah seminar desain skripsi dan mata kuliah kaiwa chukyu kohan. Dari ketiga RPS di atas belum ada yang menggambarkan nilai-nilai konservasi FBS yakni humanis, ketiga RPS tersebut hanya menjelaskan nilai-nilai konservasi tetapi tidak mengacu pada nilai konservasi FBS.

Berdasarkan hasil evaluasi, maka RPS mata kuliah seminar desain skripsi dan mata kuliah kaiwa chukyu kohan perlu adanya revisi pada CPMK, nilai-nilai konservasi UNNES digambarkan sesuai dengan FBS. Sedangkan RPS mata kuliah nihonjijo perlu adanya revisi pada CPL mengacu KKNI dan CPMK disusun dengan menggambarkan nilai-nilai konservasi FBS

\section{REFERENSI}

Abdul, M. (20II). Mengembangkan Standar Kompetensi Guru. Bandung: Remaja Rosdakarya.

Retnnoningsih, A., \& Dkk. (2019). Konservasi Berkelanjutan Tahun 2019. Semarang: UNNES Press.

Sanusi. (2016). Pengembangan Bahan Ajar Berorientasi KKNI Untuk Penguatan Scientific Approach Pada Mata Kuliah Evaluasi dan Peoses Pembelajaran Matematika. Prosiding Seminar Nasional , I 190.
Sitepu, B., \& Ika, L. (2018). Perencanaan Rencana Pembelajaran Semester dalam Proses Pemebelajaran di Perguruan Tinggi. . Perspektif Pendidikan , 44.

Yuniawan, T. (2016). Model Wacana Berwawasan Nilai-Nilai Konservasi Berbasis Ekolinguistik sebagai Pengayaan Materi Ajar Mata Kuliah Pendidikan Lingkungan Hidup. Penelitian Pendidikan , 189. 